\title{
Subject Index Vol. 20, 1997
}

\section{A6 cells 381}

Acid excretion 251

Acidosis 57

Acute renal failure 271

tubular necrosis 271 Adrenalectomy 31 Adriamycin nephropathy 44 Advanced renal failure 82 Africanized bees 271 Albuminuria 74 Aldosterone 31 Amiloride 31 Aminoguanidine 211 Ammonia 57 Angiotensin 233

antagonists, kidney function 297 Angiotensin-1 vs. angiotension-2 blockers 297 Angiotensin2 antagonist vs angiotensin-converting enzyme

inhibitor, canine kidney 391 Angiotensin-converting enzyme inhibition 1

- inhibitor 74 Antibiotic 264 Antithymocyte antibody 11 Aortoarteritis 285 Aprotinin clearance 225 Arterial stiffness 82

tone 355 Arthritis 62

Atrial natriuretic factor 18

- $\quad$ - peptide 406

Autoregulation 1, 6

Bees 271 Bee venom 271 Bicarbonate reabsorption 251 Blood vessel 372

Calcium channel(s) 381

- blocker 74

current 355

Capillary hydraulic conductivity (Lp) 25

Captopril 391

Cellular autophagy 258

Cephaloridine toxicity 264

Chloride 302

Chronic renal failure 372

Ciclosporin, nephrotoxicity 38

Cilostamide 307

Cortical tubule 398

Cultured cells 264

Cyclooxygenase 398

Cytosolic calcium 290

Diabetes 251,258

Diabetic nephropathy 74

Dichlorphenamide 240

Differentiation 355

Dihydropyridines 355

Distal nephron lithium reabsorption 31 
- $\quad$ tubule 258

Diuresis 18

Diuretics 240

Eicosanoid 398

Electron microscopy 258

Endothelin 6, 372

Envenomation 271

Enzyme-linked immunosorbent assay 38

Erythropoietin 406

Essential hypertension 406

Estrogen 51

EXP3174 391

Female rats 44 Fractional compensation 225 Fura-2 381 Furosemide 240

G proteins 355

Gene expression 355

Glomerular albumin permeability ( $\left.\mathrm{Pa}^{1 / 8 u m i n}\right) 25$

basement membrane 218

ultrafiltration coefficient 11 Glomerulosclerosis 44, 51 Glomerulus 372

Gordon's syndrome 64

Gout 62

GPI protein 411

Henle's loop transport 240 Heparan sulfate proteoglycans 218 Hypertension

71,74,82,290,372 -, salt-sensitive, salt-resistant 218

Imairats 51

Insulin 258

Intracellular stores 381

Ion current 302

Islet transplantation 258

3-Isobutyl-1-methylxanthine 307

Isozymes 307

Kidney 6,211

function, angiotensin antagonists 2971

proximal tubule 264

KARGEÍl

(C) 1997 S. KargerAG, Basel

421

E-Mail karger@,karger.ch Fax+ 41613061234 http://www. karger. ch

L-type channels 355 Large conduit arteries 82

Macula densa 240 Medullary tubule 398 Mesangial cells 302

- contraction 25

Methoxymethyl-IBMX 307

Mibefradil 355

Micropuncture 233

Morphine 18

Mycobacterium avium-intracellulare 62 
Natriuresis 18 Nerves 18 Nifedipine 381 Nitric oxide 211

- $\quad$ - synthase 211

Nonpharmacological blood pressure management

71

1,25-(OH)2D 247 OKY-046 38 Ovariectomy 44 OxonolVI 381

Permeable filter 264

Pertussis toxin 355

Phosphodiesterase 307

Phospholipase 398

Plasma renin activity 406

Platelet-activating factor 25

Polyanionic sites 218

Potassium deficiency and excretion 31

Pressure-natriuresis 1

Primary hyperparathyroidism 290

Proliferation 355

Protein degradation 258

Proximal acidification 251

PTH 247

reabsorption 240

Radioimmunoassay 372 Rat 18,57

- $\quad$ nephron 307

Remnant kidney 372 Renal blood flow 6, 225

calbindin-D28k 247

dipeptidase 411

function 211

glomerular hemodynamics 391

handling, uric acid 64

hemodynamics 11

hypouricemia 64

transplant 62

vascular resistance 225 Renin-angiotensin system 1 Renovascular hypertension 285 Rolipram 307

Salt 71

- $\quad$ sensitivity 71

Sex differences, glomerulosclerosis 51

Single nephron GFR 240

Sodium 71

Spontaneously hypertensive rat 6

Stereology 258

Sympathetic nervous system 290

T-type channels 355

Testosterone 44, 51

Thiazide diuretics 247

Thromboxane synthase inhibitor 38

Transgenic animals 1 
Tubular reabsorption 233

Tubuloglomerular feedback 233

Two-chamber system 264

Two-kidney, one-clip hypertensive rat 225

Ultrastructure 38 Urea 57

- $\quad$ cycle 57

Urinary dipeptidase 411

- $\quad$ calcium 247

Vascular resistance 11 Volume regulatory decrease 381

Water immersion 406

422

Kidney Blood Press Res Vol. 20,1997

Subject Index 